\title{
ANTI-NUCLEOSOME ANTIBODIES - A NOVEL TEST IN SYSTEMIC LUPUS ERYTHEMATOSUS
}

\author{
Pavel Horák ${ }^{\mathrm{a}}$, Zuzana Heřmanováb, Vlastimil Ščudla ${ }^{\mathrm{a}}$, Ladislav Faltýnek ${ }^{\mathrm{a}}$, Zdeněk Pospíšil ${ }^{\mathrm{a}}$ \\ a III. Department of Internal Medicine, University of Olomouc, I. P. Pavlova 6, 77520 Olomouc, Czech Republic, \\ e-mail: horakpavel@hotmail.com \\ b Department of Clinical Immunology, University of Olomouc, I. P. Pavlova 6, 77520 Olomouc, Czech Republic.
}

Received July 18, 2000

Key words: Systemic lupus erythematosus (SLE) / Anti-nucleosome antibodies / ECLAM index / Thrombomodulin

In this study the serum levels of specific anti-nucleosome autoantibodies (autoAb) were measured in the follow up of the group of SLE patients and compared to the levels of anti-dsDNA, C3, C4 components of complement, to ECLAM- European Lupus Activity Measure and to the levels of sVCAM-1, sICAM-1, neopterin, sIL-2r, IL-10 and fas ligand. Anti-nucleosome antibodies were detected using an enzyme immunoassay for the quantitative determination of auto $\mathrm{Ab}$ to nucleosomes and their components in the human serum in the group of 52 patients, 50 of them female, who all fulfilled criteria of SLE according to ACR (American Colledge of Rheumatology). Anti-nucleosome antibodies were followed up during 3 subsequent measurements during six months and compared to the development of ECLAM index, the levels of anti ds-DNA antibodies and C3, C4 complement components levels and other activity markers.

The probands with the stable low disease activity had the lowest levels of anti-nucleosome Ab (83 $\pm 33.0 \mathrm{IU} / \mathrm{ml})$. The patients with the stable high or increasing activity had the mean titers in the first series $200.42 \pm 36 \mathrm{IU} / \mathrm{ml}$ and $192 \pm 65 \mathrm{IU} / \mathrm{ml}$ and $188 \pm 58.11 \mathrm{IU} / \mathrm{ml}$ in the 2 . and 3. serial measurement. Subgroup with the high starting activity and with decrease of the activity index had the mean levels of $223 \pm 39.0 \mathrm{IU} / \mathrm{ml}, 185.6 \pm 37.6 \mathrm{IU} / \mathrm{ml}$ and $207 \pm 55.5 \mathrm{IU} / \mathrm{ml}$ during three measurements. In the subgroup of patients with lupus nephritis (LN) $n=15$, the anti-nucleosome $\mathrm{Ab}$ levels were $176 \pm 34.0 \mathrm{IU} / \mathrm{ml}, 174 \pm 30.0 \mathrm{IU} / \mathrm{ml}$ and $148 \pm 32.0 \mathrm{IU} / \mathrm{ml}$. A strong correlation was found between levels of anti-nucleosome and anti-dsDNA antibodies. All sera with anti-dsDNA antibodies over 40 had at the same time positive titer of anti-nucleosome antibodies, however, 21 sera with negative anti-dsDNA had positive test for antinucleosome antibodies. Anti-nucleosome antibodies correlated with ECLAM activity index and reversibly with C4. No correlation was established with levels of C3, sVCAM-1, sICAM-1, IL-10, fas ligand, neopterin and sIL2r. The examination of anti-nucleosome $\mathrm{Ab}$ contributes to the early diagnosis and is an instrument in the differential diagnosis of the connective tissue diseases and it seems to be especially valuable in anti-dsDNA negative lupus. The use of anti-nucleosome antibodies measurement as a marker of disease activity deserves further evaluation.

\section{INTRODUCTION}

Systemic lupus erythematosus (SLE) is a disease characterized by the B cell hyperactivity associated with production of autoantibodies directed against components of cell and by tissue depositions of immune complexes, leading to organ damage ${ }^{1}$.

Antibodies against double-stranded DNA (dsDNA) present in 40-60\% of cases of the human lupus as well as in the mouse lupus model are the key marker of SLE and their plasma levels tend to fluctuate according to the disease activity. Anti-dsDNA/DNA immune complexes have been considered responsible for the development of lupus nephritis ${ }^{2,3}$. But these complexes are difficult to demonstrate and murine and human lupus sera showed low levels of circulating DNA immune complexes $^{4,5}$. Currently, the evidence has accumulated on the important role, which defect apoptosis might play in SLE pathogenesis ${ }^{3,6,7}$. At the same time the attention is attracted to the nucleosome ${ }^{8,9}$, the unit of chromatin and the product of cell apoptosis. The nucleosome consists of the core particle composed of an octamer of histones around which the helical DNA is wrapped and histone $\mathrm{H} 1$, which is located at the point, where DNA enters and exits the nucleosome ${ }^{10}$. Some studies have demonstrated the ability of anti-dsDNA and antihistone lupus antibodies to react with certain target epitopes of the nucleosome ${ }^{11}$. Specific anti-nucleosome antibodies which only target the native nucleosome particle, but not the individual components (DNA anti histone), occur early in the disease and precede the formation of anti-dsDNA and antihistone antibodies ${ }^{12}$, 13. The nucleosome has been identified to be the most important immunogen in SLE pathogenesis, but the clinical significance of specific anti-nucleosome antibodies has not been established yet. The serum reactivity to nucleosome was demonstrated in $70-80 \%$ of lupus 
patients, which is far more that positivity of anti-dsDNA antibodies and can be demonstrated in the early phase of the disease ${ }^{14}$.

In this study we measured in the follow up of the group of SLE patients the serum levels of specific antinucleosome antibodies and compared them to the levels of anti-dsDNA, C3, C4 components of complement, to disease activity index (ECLAM- European Lupus Activity Measure $)^{15}$ and to the levels of some newer SLE activity markers as molecules sVCAM-1, sICAM1, neopterin, sIL-2r IL-10, fas ligand and thrombomodulin.

\section{MATERIALS AND METHODS}

\section{Patients}

Anti-nucleosome antibodies were measured in the group of 52 patients, 50 of them female, mean age 39 years (20-73), mean duration of disease 4 years $(0-20)$, who all fulfilled at least 4 criteria of SLE according to ACR (16). Anti-nucleosome antibodies were followed up during 3 subsequent measurement during six months and compared to the development of ECLAM system, the levels of anti ds-DNA antibodies and the C3, C4 components of complement levels.

The patients received the following treatment: Twelve patients received corticosteroid in low dose (prednison $\leq 7.5 \mathrm{mg}$ /day), four patients antimalarials, one patient methotrexate and one patient azathioprine as the single treatment. The rest of the group received the combined drug treatment: Five patients antimalarials and low dose cortikosteroid, one patient methotrexate and corticosteroid $>7.5 \mathrm{mg} / \mathrm{day}$, ten patients azathioprine and corticosteroid $>7.5 \mathrm{mg} /$ day, ten patients cyclophosphamide with corticosteroid $>7.5 \mathrm{mg} /$ day and eight patients cyclosporin A with corticosteroid $>7.5 \mathrm{mg} /$ day. All patients treated with cyclophosphamide (10) had active lupus nephritis, four of those were classified as III.B, two were IV.B according to WHO classification, the renal biopsy was not performed in four patients. In patients treated with cyclosporin (8) the lupus nephritis was present in 5 of them, and was documented by histology in 3 patients (one III.A, one IV.B, one V.A)

\section{Methods}

Anti-nucleosome antibodies were detected with commercial test Medizym anti-Nucleo (Medipan Diagnostica, Selchow, Germany). It is an enzyme immunoassay for the quantitative determination of autoAb to nucleosomes and their components in human serum. AutoAb of diluted patient samples and standard react with nucleosome antigen immobilized on the solid phase of a microtiter plate. Medizym guarantees the specific binding of nucleosome autoAb of the specimen under investigation by employing highly purified nuclesome antigen for coating. The interpretation of quantitative evaluation of antibodies is the following: $\geq 25 \mathrm{IU} / \mathrm{ml}$ positive, $<25 \mathrm{IU} / \mathrm{ml}$ negative.

Anti ds-DNA antibodies were detected also by ELISA (set Ubi-Magiwel, Mountain View, CA, USA) with the following evaluation: $<30 \mathrm{IU} / \mathrm{ml}$ negative, 30-40 IU/ml borderline positive, $>40 \mathrm{IU} / \mathrm{ml}$ positive.

The levels of $\mathrm{C} 3$ and $\mathrm{C} 4$ components of complement were measured by nephelometry using the diagnostic antiserum Behringer AG, Marburg, Germany, with normal values for C3 $0.65-1.45 \mathrm{~g} / 1$, for C4 $0.18-0.50 \mathrm{~g} / \mathrm{l}$.

Commercial ELISA sets were used for measurement of sVCAM-1, sICAM-1 (both R\&D Systems, Abingdom, UK), neopterin (Milenia, DPPC, LA, USA), sIL-2r (Immunotech International, Marseille, France), IL-10 (R\&D Systems, Abingdom, UK) and fas ligand (MBL Co., Nagoya, Japan). Pearson correlation test and ANOVA test were used for statistical evaluation of results.

\section{RESULTS}

According to ECLAM index the group could be divided into 3 subgroups with

1. Stabilized disease activity (ECLAM index $\leq 3$ and the difference in ECLAM index during the period of follow up $\leq 1$ ) - subgroup A 22 patients

2. High and/or rising activity (ECLAM $>3$ and/or the difference $>+1$ in ECLAM score) - subgroup B 12 patients

3. Declining activity (ECLAM $>3$ and the difference between ECLAM score during the follow up $\leq-1$ ) subgroup C 18 patients.

Anti-nucleosome antibodies: The mean level of antinucleosome antibodies during the first series of measurement were $159,0 \pm 33 \mathrm{IU} / \mathrm{ml}$, during the second $157 \pm 22.0 \mathrm{IU} / \mathrm{ml}$ and during the third $165 \pm 33.0 \mathrm{IU} / \mathrm{ml}$. A strong correlation was found between the levels of anti-nucleosome and anti-dsDNA antibodies $(r=0.58$, $\mathrm{p}=0.000006)$. All sera with anti-dsDNA antibodies over 40 had at the same time positive titer of antinucleosome antibodies, however, 21 sera with negative antidsDNA had positive test for anti-nucleosome antibodies. Weaker but still significantly anti-nucleosome antibodies correlated with ECLAM activity index $(\mathrm{r}=0.32$ $\mathrm{p}=0.01)$ and reversibly with $\mathrm{C} 4(\mathrm{r}=-0.30, \mathrm{p}=0.02)$ See fig. 1. There was some trend toward relation with $\mathrm{C} 3(\mathrm{r}=-0.23, \mathrm{p}=0.09)$ and $\operatorname{sICAM}(\mathrm{r}=0.23, \mathrm{p}=0.09)$, which did not reach the level of $5 \%$ significance. No correlation was established with levels of sVCAM, IL-10, fas ligand, neopterin and sIL2r.

In three subgroups of patients divided according to ECLAM activity the following results were obtained: the subgroup A with 22 patients with the stable low disease activity had the mean levels of anti nucleosome antibodies $83 \pm 33.0 \mathrm{IU} / \mathrm{ml}$ in 1 .series of measurement, followed by $55.62 \pm 22.50 \mathrm{IU} / \mathrm{ml}$ and $35.71 \pm 13.45 \mathrm{IU} / \mathrm{ml}$ in the second respectively third series. Subgroup B with 12 patients characterized by the stable high or increa- 
sing activity the mean anti-nucleosome $\mathrm{Ab}$ titers were during the first series 200.42 $\pm 36.0 \mathrm{IU} / \mathrm{ml}$ and $192 \pm 65 \mathrm{IU} / \mathrm{ml}$ and $188 \pm 58.11 \mathrm{IU} / \mathrm{ml}$ in the 2 . and 3 . serial measurement. Finally, subgroup C (18 patients) with the high starting activity and with decreasing trend of ECLAM activity index during the follow up, as defined above, had the mean levels of anti-nucleosome plasma activity of $223 \pm 39.0 \mathrm{IU} / \mathrm{ml}, 185.6 \pm 37.6 \mathrm{IU} / \mathrm{ml}$ and $207 \pm 55.5 \mathrm{IU} / \mathrm{ml}$ during three measurements. In subgroup of patients with lupus nephritis (LN) $n=15$, the anti-nucleosome levels were $176 \pm 34.0 \mathrm{IU} / \mathrm{ml}$, $174 \pm 30.0 \mathrm{IU} / \mathrm{ml}$ and $148 \pm 32.0 \mathrm{IU} / \mathrm{ml}$.

A significant differences in anti-nucleosome $\mathrm{Ab}$ levels were found between the subgroups $A$ and $B(p=0.007)$, $\mathrm{A}$ and $\mathrm{C}(\mathrm{p}=0.001)$ and $\mathrm{A}$ and $\mathrm{LN}(\mathrm{p}=0.002)$, but not between $\mathrm{B}$ and $\mathrm{C}$ and $\mathrm{LN}$, and either series of measurement showed significant changes in antibody levels. For comparison of the characteristics of subgroups and results see Table 1 and 2 and Fig. 2.

In seven patients the anti-nucleosome antibodies could be obtained at five or six occasions. The comparison of anti-nucleosome and anti-dsDNA antibody profiles is in the Fig. 3.

Table 1. Anti-nucleosome levels in subgroup A, B, C, LN in the serial measurement

\begin{tabular}{|l|l|l|l|l|}
\hline $\begin{array}{l}\text { subgroup } \\
\text { and series }\end{array}$ & $\begin{array}{l}\text { anti } \\
\text { nucle } \\
\text { some } \\
\mathrm{Ab} / \overline{\mathrm{x}}\end{array}$ & $\begin{array}{l}\text { Min- } \\
\max \end{array}$ & $\begin{array}{l}\text { Median } \\
\mathrm{M}\end{array}$ & $\begin{array}{l}\text { Stand. } \\
\text { dev. } \\
\delta\end{array}$ \\
\hline
\end{tabular}

\begin{tabular}{|l|l|l|l|l|}
\hline A I. & 81.0 & $12-644$ & 15.0 & 149.6 \\
\hline A II. & 55.6 & $12-144$ & 17.0 & 62.6 \\
\hline A III. & 35.7 & $11-109$ & 25.5 & 35.5 \\
\hline B I. * & 200.4 & $12-625$ & 184.5 & 184.5 \\
\hline B II. * & 192.0 & $12-527$ & 180 & 207.7 \\
\hline B III. * & 188 & $12-400$ & 185 & 174.0 \\
\hline C I. * & 223.7 & $12-539$ & 255 & 164.5 \\
\hline C II. * & 185.6 & $12-518$ & 190 & 151.2 \\
\hline C III. * & 207 & $15-478$ & 190 & 166.5 \\
\hline LN I. * & 176.8 & $12-414$ & 190.0 & 162.3 \\
\hline LN II. * & 174.4 & $12-471$ & 185 & 148.2 \\
\hline LN III. * & 148 & $12-478$ & 140 & 142 \\
\hline
\end{tabular}

min-max - minimal and maximal values stand. dev. - standard deviation

ANOVA statistic, $<0.05$

* statistically significant difference between subgroups B,C and LN on one and subgroup $\mathrm{A}$ on the other side during three series of measurements.
Table 2. Characteristics of subgroups A, B, C LN (A - stabilized, B high and/or increasing activity, $\mathrm{C}$ - decreasing activity according to ECLAM system; LN patients with lupus nephritis) I, II, III. serial measurement

\begin{tabular}{|l|l|l|l|l|}
\hline $\begin{array}{l}\text { Subgroup } \\
\text { and series }\end{array}$ & $\begin{array}{l}\text { ECLAM } \\
\end{array}$ & dsDNA Ab & C3 & C4 \\
& & IU/ml, $/ \bar{x}$ & $/ \bar{x}$ & $/ \bar{x}$ \\
& & $g / l$ & $g / l$ \\
\hline
\end{tabular}

\begin{tabular}{|l|l|l|l|l|}
\hline A I. & 1.7 & $22.29( \pm 20.0)$ & 0.77 & 0.19 \\
\hline A II & 1.7 & $10.5( \pm 14.2)$ & 0.76 & 0.18 \\
\hline A III. & 1.8 & $13.25( \pm 10.0)$ & 0.75 & 0.19 \\
\hline B I. & 3.7 & $85.12( \pm 79.1)$ & 0.60 & 0.15 \\
\hline B II. & 4.2 & $109.9( \pm 62.1)$ & 0.60 & 0.14 \\
\hline B III. & 4.4 & $90.37( \pm 62.9)$ & 0.65 & 0.14 \\
\hline C I. & 4.0 & $77.83( \pm 77.8)$ & 0.56 & 0.15 \\
\hline C II. & 3.0 & $57.81( \pm 54.6)$ & 0.61 & 0.16 \\
\hline C III. & 2.4 & $39.91( \pm 21.0)$ & 0.68 & 0.17 \\
\hline LN I. & 5.0 & $90.07( \pm 76.5)$ & 0.50 & 0.14 \\
\hline LN II. & 3.3 & $73.53( \pm 60.97)$ & 0.59 & 0.12 \\
\hline LN III. & 3.4 & $75.44( \pm 55.0)$ & 0.58 & 0.15 \\
\hline
\end{tabular}

\section{DISCUSSION}

The results of the measurement and the statistical analysis are encouraging in respect of the practical use of anti-nucleosome antibodies as a potential marker of SLE. Serum levels of anti-nucleosome antibodies correlate with anti ds-DNA antibodies, which is a recognized test for SLE and also one of the ACR criteria for the disease. Nevertheless, there is not a complete overlap of positivity for these two tests. High levels of anti-nucleosome antibodies have been found in 21 sera with no anti-ds-DNA reactivity, however, not vice versa. Antinucleosome specific antibodies represent the early marker of SLE recognizing conformational epitopes shared by the native nucleosome molecule ${ }^{13}$. Later, the autoimmune response can diversify to the components of the nucleosomes, DNA and histones as a part of the intermolecular spreading. Anti nucleosome antibodies are also relatively specific for SLE, besides SLE they were detected just in the mixed connective tissue disease (MCTD) and systemic scleroderma ${ }^{14}$. They were absent in patients with inflammatory myopathies, primary Sjögren's syndrome, RA, primary antiphospholipid syndrome, Wegener's granulomatosis, giant cell arteritis, Takayasu arteritis, relapsing polychondritis, sarcoidosis, Behcet disease and hepatitis $\mathrm{C}$ virus infection ${ }^{14}$.

The significant correlation with ECLAM index and $\mathrm{C} 4$ demonstrates anti-nucleosome $\mathrm{Ab}$ as a possible marker of the disease activity, although according to the results of this study anti-dsDNA antibodies seem to response to the changing disease activity better. In the subgroup of patients with stabile disease with low activity the trend to low levels of anti-nucleosome antibodies was observed, thus this subgroup significantly differed 

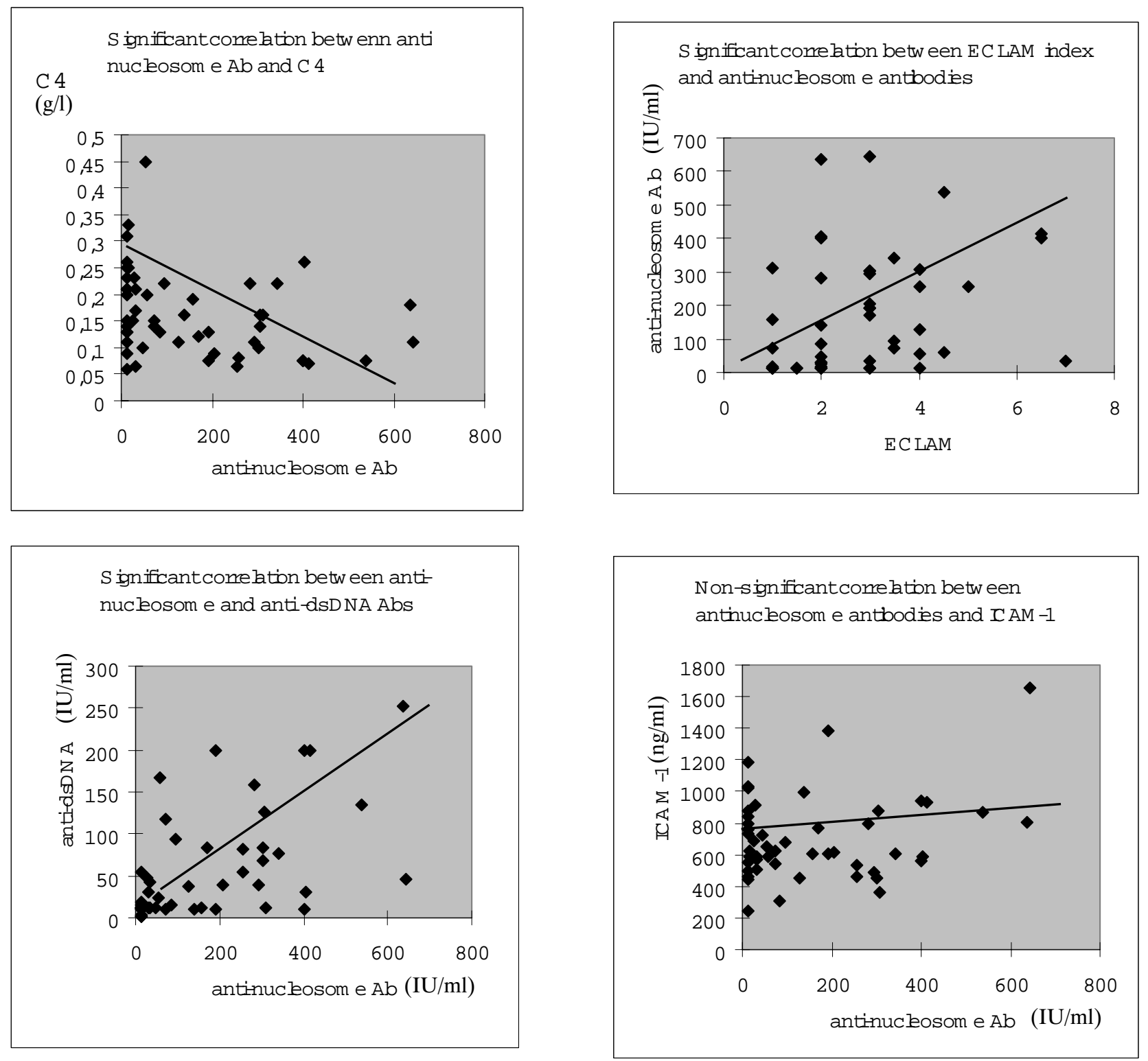

Fig. 1 Correlations associated with anti-nucleosome antibodies in the group of 52 lupus patients

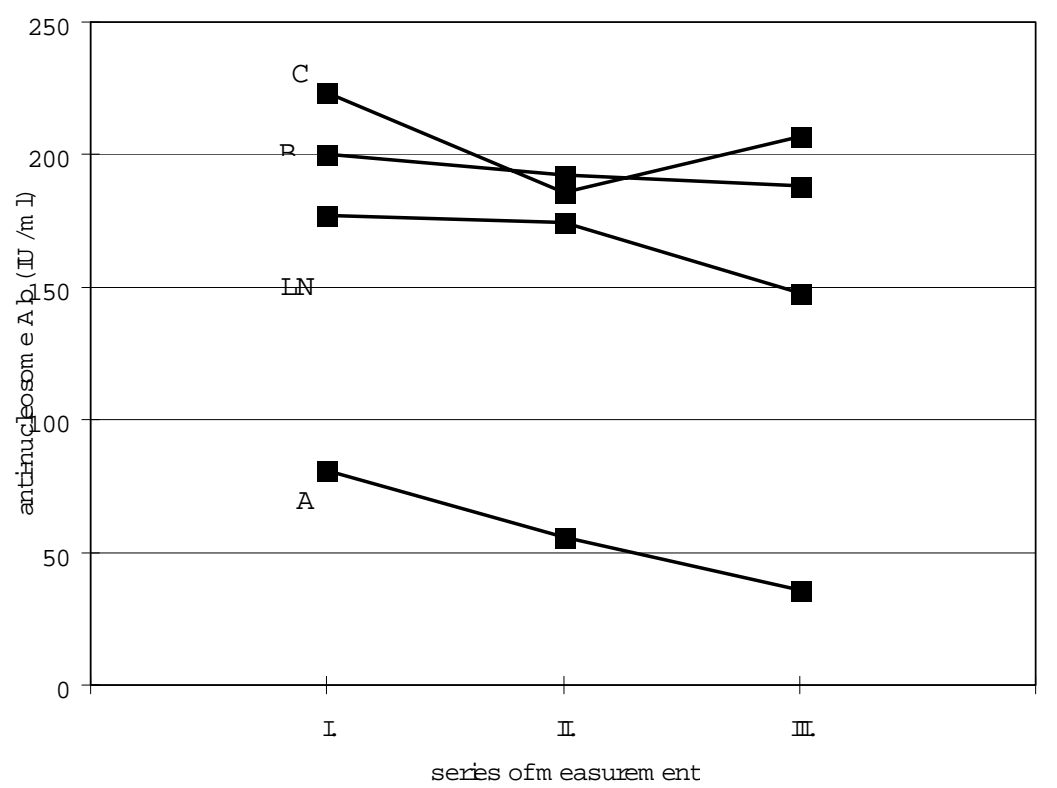

Fig. 2 Development of anti-nucleosome antibodies mean levels in patients with stabile (A), rising (B) and dicreasing (C) disease activity index and in patients with lupsu nephritis (LN) 

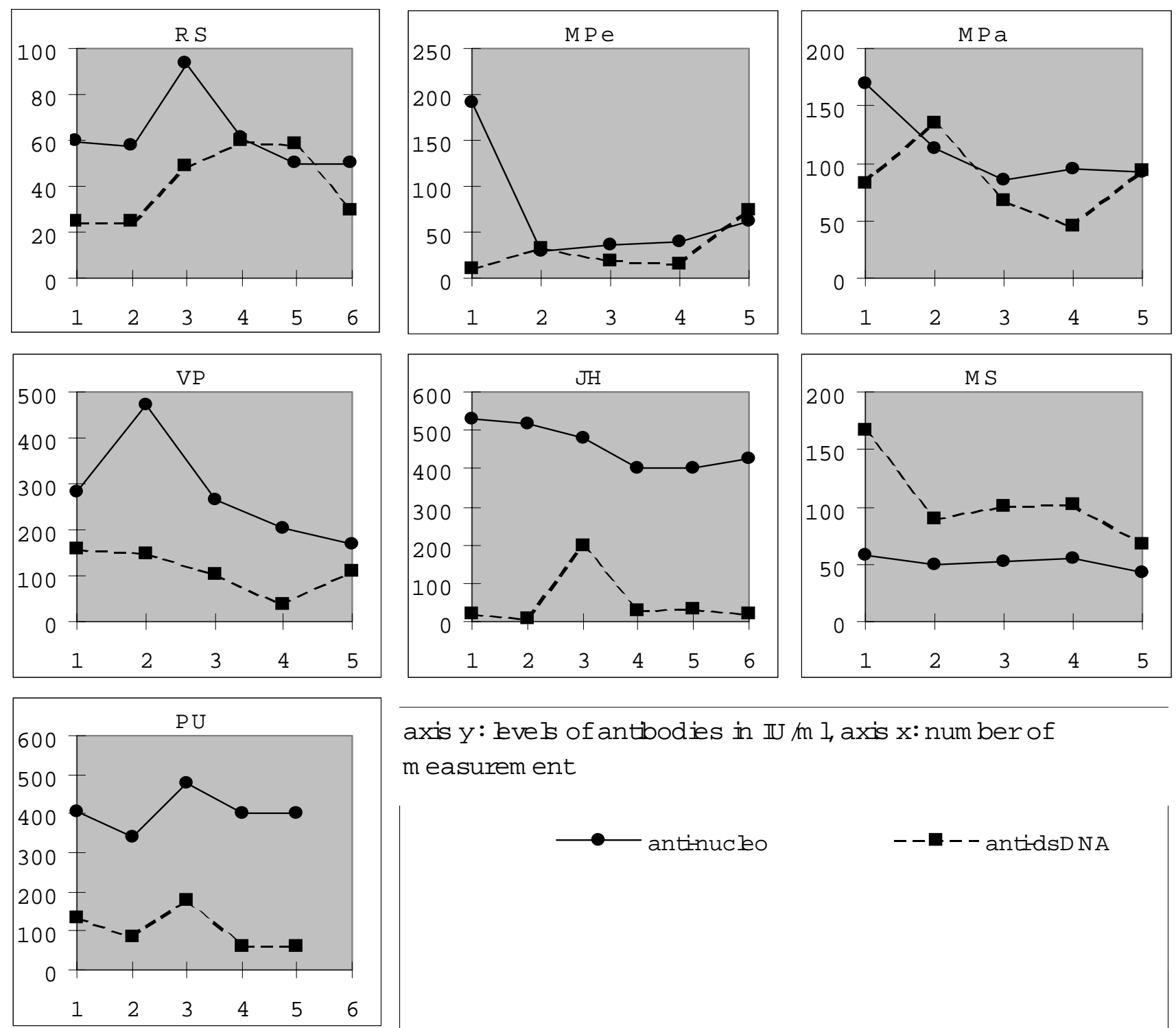

axis $y$ : levels of antibodies in $\mathbb{U} / \mathrm{m} l$, axis $x$ : num ber of m easurem ent

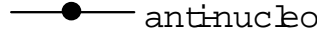

Fig. 3 Development of anti-nucleosome and anti-dsDNA antibodies in seven patients during the five of six measurements

from the others (active disease, lupus nephritis). In the subgroup of probands with decreasing disease activity according to ECLAM system and with response seen also in anti-dsDNA levels, no significant decline in antinucleosome antibodies was observed.

The high levels of anti-nucleosome antibodies were also found in patients with lupus nephritis regardless of their overall disease activity. It supports the concept of nucleosome and anti-nucleosome complexes as the major pathogenic agent in lupus nephritis, 9, 17,18.

One of the most striking features of SLE is the production of auto-antibodies targeting the chromatin components as deoxyribonucleic acid, ribonucleic acid and histones. Mammalian DNA was proved to be not immunogenic, immunization with mammalian DNA does not induce pathogenic anti DNA antibodies ${ }^{19}$. Burlingame et al. were the first to show that the production of anti-chromatin antibodies is induced by $\mathrm{T}$ cell dependent immune response with selfantigen ${ }^{20}$. Recent findings in murine and human lupus strongly suggest that the initial autoimmune response is directed against nucleosomes ${ }^{17,18}$.

There are many unanswered question remaining, such as the timing of anti dsDNA production after the immune answer to nucleosome, the predictive value of anti-nucleosome antibodies for lupus flare and the mechanisms of contributions of various antibodies to the development of tissues damage. Understanding to the last could have in the future a major impact not only on our understanding the lupus pathogenesis, but can help to improve the treatment of SLE.

In conclusion it should be emphasized that the determination of anti-nucleosome as the earliest antibody in SLE contributes to the diagnosis and is an instrument in differential diagnoses of connective tissue diseases and it seems to be especially valuable in anti-dsDNA 
negative lupus. Use of anti-nucleosome antibody measurement as a marker of disease activity deserves further evaluation.

\section{ACKNOWLEDGMENT}

The financial support by IGA $\check{C} R$ No NK/4616-3.

\section{REFERENCES}

1. Gilbert, D., Brard, F., Jovelin, F., Tron, F. (1996) Do naturally accurring autoantibodies participate in the constitution of the pathological B-cell repertoire in systemic lupus erythematosus? J. Autoimmun., 9, 247-257.

2. Amoura, Z., Piette, J. Ch., Bach, J. F., Koutouzov, S. (1999) The key role of nucleosomes in Lupus. Arthritis Rheum., 42, 833-843.

3. Vlahakos, D. V., Foster, M. H., Adams, S., Katz, M., Ucci, A. A., Barrett, K. J., Datta, S. K., Madaio, M. P. (1992) Anti-DNA antibodies form immune deposits at distinct glomerular and vascular sites. Kidney Int., 41, 1690-1700.

4. Izui, S., Lambert, P. H., Miescher, P. A. (1977) Failure to detect circulating DNA-anti-DNA complexes by four radioiminological methods in patients with systemic lupus erythematosus. Clin. Exp. Immunol., 30, 384-392.

5. Bernstein, K. A., Di Valerio, R., Lefkowith, J. B. (1995). Glomerular binding activity in MRL lpr serum consists of antibodies that bind to a DNA/histone/type IV collagen complex. J. Immunol., 154, 2424-2433.

6. Emlen, W., Niebur, J., Kadera, R. (1994). Accelerated in vitro apoptosis of lymphocytes from patients with systemic lupus erythematosus. J. Immunol., 152, 3685-3692.

7. Williams jr., R. C., Malone, C., Blood, B., Silvestris, F. (1999) Anti-DNA and antinucleosome antibody affinity - a mirror image of lupus nephritis? J. Rheumatol., 26, 331-346.

8. Brard, F., Gilbert, D., Jovelin, F., Tron, F. (1997) Idiopatic analysis of antinucleosome monoclonal antibodies derived from lupus mice. J. Autoimmun., 10, 425-431.

9. Suenaga, R., Mitamura, K., Abdou, N. I. (1998) Isolation of antinucleosome antibodies from the plasma of lupus nephritis patients. Clin. Rheumatol., 17, 189-194.
10. Bavykin, S. G., Usachenko, S. I., Zalensky, A. O., Mirzabekov, Z. (1990) Structure of nucleosomes and organization of internucleosomal DNA in chromatin. J. Mol. Biol., 212, 595-611.

11. Burlingame, R. W., Rubin, R. L., Balderas, R. S., Theofilopoulos, A. N. (1993) Genesis and evolution of antichromatin autoantibodies in murine lupus indicates T-dependent immunization with self antigen. J. Clin. Invest., 91, 1687-1696.

12. Amoura, Z., Chabre, H., Koutouzov, S., Lotton, C., Cabrespines, A., Bach, J. F., Jacob, L. (1994) Nucleosome restricted antibodies are detected before anti-dsDNA and/or antihistone antibodies in serum of MRL-Mp lpr/lpr and +/+ mice, and are present in kidney eluates of lupus mice with proteinuria. Arthritis Rheum., 37, 1684-1688.

13. Kramers, C., Chabre, H., Koutouzov, S., Lotton, C., Cabrespines, A., Bach, J. F., Jacob, L. (1994) Antinucleosome antibodies complexed to nucleosome antigens show anti-DNA reactivity and bind to rat glomerular membrane in vivo. J. Clin. Invest., 92, 568-580.

14. Amoura, Z., Koutouzov, S., Chabre, H., Cacoub, P., Amoura, I., Musset, L., Bach, J. F., Piette, J. C. (2000) Presence of antinucleosome autoantibodies in a restricted set of connective tissue diseases. Arthritis Rheum., 43, 76-84.

15. Bencivelli, W., Vitali, C., Isenberg, D. A., Smolen, J. S., Snaith, M. L., Sciuto, M., Bombardieri, S. (1992) and European Consensus Study Group for Disease Activity in SLE: Disease activity in SLE: Report of the consensus study group of the European workshop fpr rheumatology research. III. Development of the computerised clinical chart and its appplication to the comparison of different indices of disease activity. Clin. Exp. Rheumatol., $10,549-554$.

16. Tan, E. M., Cohen, A. S., Fries, J. F., Masi, A. T., McShane, D. J., Rothfield, N. F., Schaller, J. G., Talal, N., Winchester, R. J. (1982) The 1982 revised criteria for the classification of systemic lupus erythmatosus. Artritis Rheum., 25, 1271-1277.

17. Lefkowith, J. B., Gilkeson, G. S. (1996) Nephritogenic autoantibodies in lupus: current concepts and antinuing controversies. Arthritis Rheum., 39, 894-903.

18. Lefkowith, J. B., Kiehl, M., Rubenstein, J., DiValerio, R., Bernstein, K., Kahl, L., Rubin, R. L., Gourley, M. (1996) Heterogeneity and Clinical Significance of Glomerular-binding Antibodies in Systemic Lupus Erythematosus. J. Clin. Invest., 98, 1373-1380.

19. Madaio, M. P., Hodder, S., Schwartz, R. S., Stollar, B. D. (1984) Responsiveness of autoimmune and normal mice to nucleic acid antigens. J. Immunol., 132, 872-882.

20. Burlingame, R. W., Boye, M. L., Starkebaum, G., Rubin, R. L. (1994) The central role of chromatin in autoimmune responces to histones and DNA in systemic lupus erythematosus. J. Clin. Invest., 94, 184-192. 